\title{
Comparison of Motion Changes and Clinical Outcomes between Cervical Disc Replacement and Anterior Cervical Discectomy and Fusion in Single Level Cervical Degenerative Disease: Retrospective Analysis
}

\section{Sang-Deok Kim', Jung-Kil Lee ${ }^{1 *}$, Jae-Won Jang', Hyung-Sik Moon', Soo-Han Kim ${ }^{1}$ and Dae-Yong Kim²}

${ }^{1}$ Department of Neurosurgery, Chonnam National University Medical School \& Research Institute of Medical Sciences, Gwangju, Korea

${ }^{2}$ Department of Neurosurgery, Dong-Gwangju Woori Hospital, Gwangju, Korea

\begin{abstract}
Objective: Cervical Total Disc Replacement (CTDR) has recently been developed as an alternative to Anterior Cervical Discectomy and Fusion (ACDF) in cervical degenerative disease to preserve the motion at the treated level. The aim of this study is to investigate the safety and efficacy of CTDR by comparing it with ACDF in the treatment of single-level cervical degenerative disease, retrospectively.
\end{abstract}

Methods: This study included 61 patients, who underwent either stand-alone single-level ACDF $(n=33)$ or singlelevel CTDR (Bryan cervical artificial disc, $n=28$ ) at $C 3$ to $C 7$ for degenerative cervical disease between June 2007 and December 2009. Cervical radiographs were obtained to measure overall and regional cervical angle and Range of Motion (ROM). For evaluation for patient's pain, visual analogue scale and Japanese Orthopedic Association score was measured.

Results: The changes of the overall Cervical Sagittal Angle (CSA) were not significantly different between the two groups. The Segmental Angle (SA) was maintained at a significantly higher in the CTDR group compared to the ACDF group during the follow-up period $(p<0.05)$. The ROM of the upper adjacent segment was significantly increased in the ACDF group compared to the CTDR group.

Conclusions: Clinically, CTDR is at least as efficient as ACDF. CTDR using a Bryan artificial disc provided a significant maintenance of the SA and the ROM at the treated level, and prevented the hyper-mobility at the upper adjacent segment compared to the ACDF. In the Future, prospective, randomized, long-term follow-up study with large-number will be required to clarify the efficacy of CTDR.

\section{Introduction}

Since Anterior Cervical Discectomy and Fusion (ACDF) was first introduced by Smith and Robinson, since then it has been considered the standard surgical procedure for treatment of degenerative cervical disease $[1,2]$. The goals of ACDF are to decompress the neural structures including spinal cord and nerve roots and, to provide permanent stabilization via optimal bone fusion of an index level while maintaining cervical physiologic alignment. In literatures, ACDF has provided a greater than $90 \%$ likelihood of relieving radicular symptoms and improving myelopathy [2]. However, the cervical spine is a mobile complex, ACDF results in a loss of mobility at the treated level, and it may eventually lead to kinematic strain on adjacent spinal levels and consequent disc degeneration and mechanical instability. Long term follow-up on ACDF has revealed that up to $25 \%$ of patients may develop recurrent axial or radicular symptoms for Adjacent Segment Degeneration (ASD) [3]. Furthermore, complications of ACDF, such as graft collapse, expulsion, pseudoarthrosis and instrumentation failure, have been frequently reported during the follow-up period [4]. These problems have encouraged the development of new technology as an alternative to ACDF in cervical degenerative disease; therefore, Cervical Total Disc Replacement (CTDR) has been devised and used now.

CTDR was first attempted by Fernstorm [5] and involved the placement of metallic ball bearings into the disc space of the operated segment. However, the clinical trial failed due to a high incidence of endplate subsidence and segmental hypermobility. The era of CTDR has again begun in Europe in the late 1990s, when a renewal of efforts was spurred by progress in lumbar total disc replacement with Charite artificial disc [6]. CTDR offers a theoretical advantage over ACDF in selected patients with medically refractory cervical radiculopathy or myelopathy. By preserving motion at the operated level, CTDR has the potential to decrease the occurrence of ASD. Therefore, studies about Range of Motion (ROM) and cervical sagittal balance after CTDR or $\mathrm{ACDF}$ are an essential component, because the maintenance of cervical ROM and alignment after surgery may influence the development of ASD and a patient's clinical outcomes including physical activity.

Recently, the author has performed CTDR for the treatment of cervical degenerative disease. To determine the efficacy and safety of CTDR in cervical degenerative, the author conducted a comparative study regarding cervical alignment, motion changes, development of ASD, and clinical results between CTDR and ACDF groups. In this study, the hypothesized were that CTDR may eventually provide motion preservation on treated level and good overall cervical lordosis, decrease hypermobility on an adjacent level, less development of ASD, and eventually serve favorable clinical outcome compared to ACDF. Therefore, CTDR may be a safe and effective alternative to the traditional ACDF in degenerative cervical disease.

*Corresponding author: Jung-Kil Lee, Department of Neurosurgery, Chonnam National University Hospital 671, Jebongno, Dong-gu, Gwangju, 501-757, Republic of Korea, Tel: 82-62-220-6602; Fax: 82-62-224-9865; E-mail: jkl@chonnam.ac.kr

Received March 29, 2012; Accepted April 20, 2012; Published April 23, 2012

Citation: Kim SD, Lee JK, Jang JW, Moon HS, Kim SH, et al. (2012) Comparison of Motion Changes and Clinical Outcomes between Cervical Disc Replacement and Anterior Cervical Discectomy and Fusion in Single Level Cervical Degenerative Disease: Retrospective Analysis. J Spine 1:116. doi:10.4172/2165-7939.1000116

Copyright: (๑ $2012 \mathrm{Kim} \mathrm{SD}$, et al. This is an open-access article distributed under the terms of the Creative Commons Attribution License, which permits unrestricted use, distribution, and reproduction in any medium, provided the original author and source are credited. 
Citation: Kim SD, Lee JK, Jang JW, Moon HS, Kim SH, et al. (2012) Comparison of Motion Changes and Clinical Outcomes between Cervical Disc Replacement and Anterior Cervical Discectomy and Fusion in Single Level Cervical Degenerative Disease: Retrospective Analysis. J Spine 1:116. doi:10.4172/2165-7939.1000116

Page 2 of 7

\section{Materials and Methods}

\section{Study population}

In this study randomly allocated 61 patients who underwent either single-level ACDF $(\mathrm{n}=33)$ or CTDR $(\mathrm{n}=28)$ were enrolled for the treatment of degenerative cervical disease between June 2007 and December 2009 in the department of neurosurgery of Chonnam National University Hospital. The patients were selected according to the clinical indications for stand-alone ACDF or CTDR that is described in Table 1. Patients with recent infection, ossification of the posterior longitudinal ligament, osteoporosis, severe spondylosis with loss of disc height $>50 \%$, Paget's disease, prior surgical history at the cervical lesion, or cervical instability, were excluded from this study. For ACDF, a stand-alone synthetic PolyEtherEtherKetone (PEEK) cage filled with local autologous bone chips and demineralized bone matrix (DBM) was used, and a Bryan cervical artificial disc (Medtronic Sofamor Danek, Memphis, TN, USA) was implanted for CTDR after decompression.

\section{Surgical technique of ACDF}

The patient is positioned in a neutral supine position. Preoperative fluoroscopy is used to confirm the incision site and adequate visualization of the index level. A standard transverse skin incision over the affected level and exposure of the prevertebral space were performed. Intraoperative fluoroscopy was used to confirm proper spinal alignment and localization. Discectomy was performed, followed by symmetrical central decompression with resection of the posterior anulus and posterior longitudinal ligament. Following osteophyte excision, the roots or spinal cord was totally decompressed, and the superior and inferior vertebral body end plates were decorticated. Care was taken to preserve the bony endplates; use of the high-speed drill is minimized or avoided altogether. Bone fragments obtained during resection of osteophytes were collected for grafting. The PEEK cage was packed with DBM (Grafton, Osteotech, Inc., Shrewsbury, NJ, USA) and local autologous bone chips, and then it was inserted into the decompressed disc space. Immediately after insertion of the PEEK cage, a fluoroscopic view was obtained to check the position of the PEEK cage and the alignment of the cervical spine. The operation was completed without additional cervical plate fixation. All patients were braced in a cervical collar for 4 weeks postoperatively, and early ambulation was encouraged at postoperative day 1 .

\section{Surgical technique of CTDR}

The CTDR using a Bryan cervical artificial disc is similar to ACDF. The patient was placed in the supine-neutral position with maintenance of the physical curve of the cervical spine. After symmetrical decompression of the spinal canal, midline verification was confirmed with Antero-Posterior (AP) fluoroscopy. After the decision was made on adequate size and position of the implant under fluoroscopic guidance, milling of the endplates using a drill was required to create concave surfaces on the endplates to match the convex endplates of the Bryan cervical artificial disc. The Bryan cervical artificial disc was then placed with a straightforward. Attention is paid to proper sizing. Over-sizing the disc can lead to limitation of motion, while undersizing can predispose to subsidence or Heterotopic Ossification (HO). After device placement, exposed bony surfaces were waxed, and AP and lateral fluoroscopy were used to confirm proper positioning. Early ambulation was encouraged in all patients without applying the cervical brace.

\section{Radiologic assessment}

Plain radiographs were obtained before surgery, immediately after surgery, and at 1 and, 12 months and the annually after surgery. The overall Cervical Sagittal Angle (CSA, C2-7 angle), Segmental Angle (SA) of the treated level, Range of Motion (ROM) of the cervical spine (C27), ROM of the treated level, and ROM of the upper and lower adjacent segments, were measured on simple cervical lateral radiographs. The angles for above mentioned parameters were measured by tangential method or Cobb's method. The overall CSA was measured as the angle formed by the lines drawn parallel to the lower endplates of $\mathrm{C} 2$ and C7 on a neutral simple radiograph. The SA was measured by the lines drawn parallel to the superior margin of the upper vertebral body and the inferior margin of the lower vertebral body of the treated level on a neutral simple radiograph (Figure 1). The ROM of the cervical spine was measured as the difference of the overall CSA between flexed and extended state on the dynamic cervical simple radiographs, and the ROM of the segmental level was calculated by the same method using SA measured on dynamic cervical radiographs. The angle of the upper adjacent level was measured by lines drawn parallel to the superior margin of the upper vertebral body and the superior margin of the lower vertebral body at the upper adjacent disc level. The ROM of the upper adjacent segment was measured as the difference of the angle of the upper adjacent level between flexed and extended states on dynamic cervical simple radiographs. The ROM of the lower adjacent segment was calculated using the same method (Figure 2).

In the ACDF group, fusion was defined as follows; 1) bridging trabecular bone; 2 ) angular motion less than 5 degrees; 3 ) translational motion less than $3 \mathrm{~mm}$; and 4 ) less than $50 \%$ radiolucency along the bone-implant interface. Radiological evidence of Adjacent Segment Degeneration (ASD) was defined by previously established criteria as follows; 1) new or increased narrowing of a disc space $(>30 \%) ; 2$ ) increased or new ossification of the anterior longitudinal ligament;

\section{Inclusion Criteria}

Age from 20 to 60 years

Single level symptomatic cervical degenerative disease Intractable radiculopathy to conservative management

Myelopathy attributable to cervical degeneration at single leve Symptoms and findings present between $\mathrm{C} 3$ and $\mathrm{C} 7$

Table 1: Clinical indications for ACDF or CTDR (Inclusion criteria).

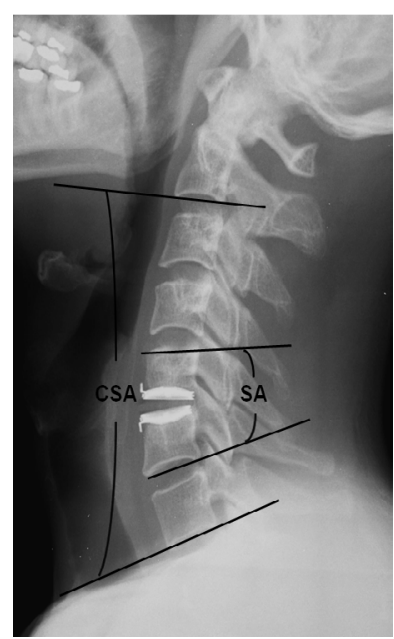

Figure 1: Overall Cervical Sagittal Angle (CSA) and Segmental Angle (SA) on neutral simple cervical radiograph. 
Citation: Kim SD, Lee JK, Jang JW, Moon HS, Kim SH, et al. (2012) Comparison of Motion Changes and Clinical Outcomes between Cervical Disc Replacement and Anterior Cervical Discectomy and Fusion in Single Level Cervical Degenerative Disease: Retrospective Analysis. J Spine 1:116. doi:10.4172/2165-7939.1000116

Page 3 of 7
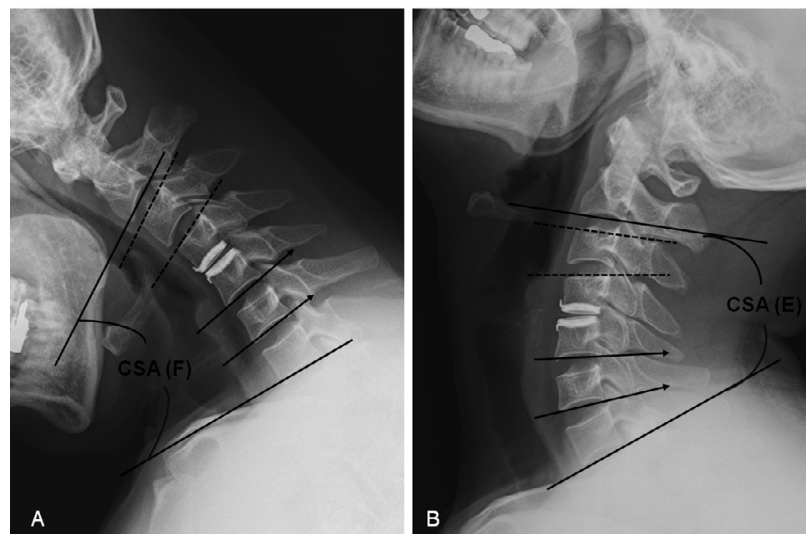

Figure 2: Range of Motion (ROM) of cervical spine; difference between CSA $(F)$ and CSA (E), angle of upper adjacent segment; angle formed by two dotted lines, ROM of upper adjacent segment; difference of angle formed by dotted line at flexion and extension, ROM of segmental level; difference of SA at flexion and extension, angle of lower adjacent segment; angle formed by two arrow lines, ROM of lower adjacent segment; difference of angle formed by arrow line at flexion and extension.

and 3) new anterior osteophyte formation or enlargement of existing osteophytes [7].

\section{Clinical assessment}

Pain and the function were assessed using the Visual Analog Scale (VAS) and Japanease Orthopedic Association (JOA) scores (Table 2). These outcome measures were completed by the patient without assistance. The preoperative and follow-up VAS for axial neck and radicular pain were assessed with the endpoint anchors of no pain $(0$ point) and severe pain (10 points). The JOA scoring system includes motor function of the upper and lower extremities, sensory function of the upper and lower extremities, and bladder function (Table 3). The JOA score has a maximum score of 17.

\section{Statistical analysis}

Demographic and, radiographic parameters and clinical outcomes of surgery with CTDR were compared between the CTDR and ACDF groups. Data were analyzed using the SPSS program for Windows V17.0 (SPSS, Chicago, IL, U.S.A.); the pared T, independent T, Fisher-exact and Mann-Whitney $U$ test was used for analyses. Data are presented as the mean \pm standard deviation. For all analyses, a p-value of $<0.05$ was considered statistically significant.

\section{Results}

Sixty-one patients (33: ACDF with stand-alone PEEK cage, 28: CTDR with Bryan cervical artificial disc) were enrolled in this study. The age population ranged from 27 to 59 years with a mean age of 46.8 years versus 43.3 years in the ACDF and CTDR groups, respectively. The average follow-up period was 26.7 months and 22.8 months in the ACDF and CTDR groups, respectively. The affected levels in ACDF group were C3-C4 in 5 patients; $\mathrm{C} 4-\mathrm{C} 5$ in 6, C5-6 in 17, C6-7 in 5. In CTDR group, the affected levels were $\mathrm{C} 3-\mathrm{C} 4$ in 3 patients; $\mathrm{C} 4-\mathrm{C} 5$ in 7, C5-6 in 14, C6-7 in 4. Preoperatively, the ACDF and CTDR groups were similar in terms of age, sex, overall CSA, SA of treated level, ROM of the cervical spine and treated level, and ROM of upper and lower adjacent segments. Clinically, preoperative VAS and JOA scores between the ACDF and CTDR groups were also similar (Table 4).

\section{Radiologic outcomes}

The mean preoperative overall CSA was $14.6 \pm 9.8$ degrees in the ACDF group and $15.7 \pm 11.7$ degrees in the CTDR group. One month after surgery, it was changed to $15.2 \pm 11.2$ degrees and $15.9 \pm 10.6$ degrees in each group, respectively. At the last postoperative followup, the overall CSA was changed to $13.9 \pm 9.8$ degrees and $16.9 \pm 13.2$ degrees in each group, respectively. Although the follow-up change of the cervical lordotic angle was slightly higher in the CTDR group than that of the ACDF group, there were no significant differences of overall CSA during the follow-up period between the two groups ( $p>0.05)$. The SA at the treated level in a neutral radiograph was changed from $2.6 \pm 4.1$ degrees to $3.6 \pm 4.9$ degrees in the ACDF group at one month after surgery, and it decreased to $2.1 \pm 3.7$ degrees at the last follow-up. There was no statistical significance between the preoperative and last follow-up SA of the treated level in ACDF group ( $p>0.05$ ). In CTDR group, the SA at the treated level was changed from $2.9 \pm 3.2$ degrees to $5.7 \pm 5.2$ degrees at one month after surgery, and it was slightly decreased to $5.3 \pm 4.2$ degrees at the last follow-up. Statistically, the last follow-up SA of the treated level was significantly higher than the preoperative angle in CTDR $(\mathrm{p}<0.05)$. In addition, there was statistical significance in SA at the last follow-up between the ACDF and CTDR groups $(\mathrm{p}<0.05)$ (Figure 3$)$.

The preoperative cervical spine ROM was $37.2 \pm 11.7$ degrees in the ACDF group and $40.3 \pm 13.5$ degrees in the CTDR group. One month after surgery, it was decreased to $30.7 \pm 10.1$ degrees and 32.6 \pm 10.3 degrees each, respectively. At the last follow-up, it was changed to $36.9 \pm 12.9$ degrees in the ACDF group and $43.9 \pm 16.3$ degrees in the CTDR group. Although the overall cervical spine ROM at 12 months after surgery and the last follow-up was higher in the CTDR
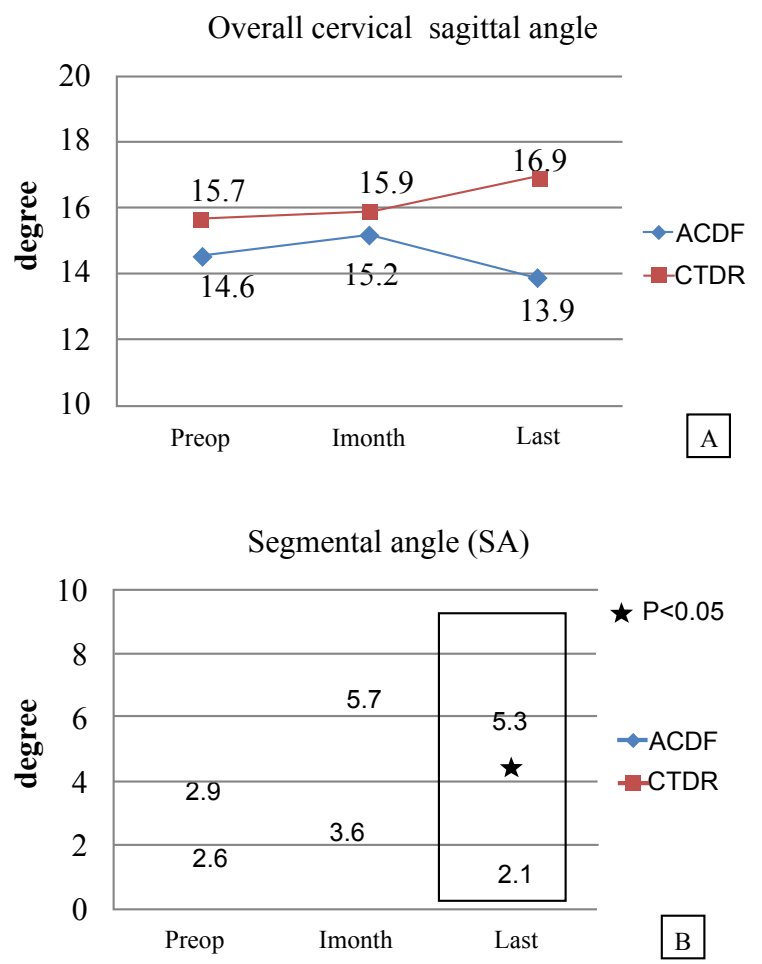

Figure 3: The changes of overall Cervical Sagittal Angle (A) and Segmental Angle of treated level (B). 
Citation: Kim SD, Lee JK, Jang JW, Moon HS, Kim SH, et al. (2012) Comparison of Motion Changes and Clinical Outcomes between Cervical Disc Replacement and Anterior Cervical Discectomy and Fusion in Single Level Cervical Degenerative Disease: Retrospective Analysis. J Spine 1:116. doi:10.4172/2165-7939.1000116

Page 4 of 7

\begin{tabular}{|c|c|c|}
\hline \multicolumn{2}{|l|}{ Category } & \multirow[t]{2}{*}{ Score } \\
\hline Motor function & & \\
\hline Upper extremity & $\begin{array}{l}\text { o unable to feed oneself w/any tableware including chopsticks, spoon, or fork, /or unable to fasten button of any size } \\
\text { ocan manage to feed oneself w/spoon \&/or fork but not w/chopsticks } \\
\text { o either eating w/chopsticks writing is possible but practical, \& or large button can be fastend } \\
\text { o either eating w/chopsticks writing is clumsy but practical, \&or cuff button can be fastend } \\
\text { o normal }\end{array}$ & $\begin{array}{l}0 \\
1 \\
2 \\
3 \\
4\end{array}$ \\
\hline Lower extremity & $\begin{array}{l}\text { ounable to stand \& walk by any means } \\
\text { ounable to walk w/o a cane or other support on a level } \\
\text { owalks independently on a level but needs support on stairs } \\
\text { ocapable of fast but clumsy waling } \\
\text { onormal }\end{array}$ & $\begin{array}{l}0 \\
1 \\
2 \\
3 \\
4\end{array}$ \\
\hline \multicolumn{3}{|l|}{ Sensory function } \\
\hline Upper extremity & $\begin{array}{l}\text { oapparent sensory disturbance } \\
\text { ominimal sensory disturbance } \\
\text { onormal }\end{array}$ & $\begin{array}{l}0 \\
1 \\
2\end{array}$ \\
\hline Lower extremity & $\begin{array}{l}\text { oapparent sensory disturbance } \\
\text { ominimal sensory disturbance } \\
\text { onormal }\end{array}$ & $\begin{array}{l}0 \\
1 \\
2\end{array}$ \\
\hline Trunk & $\begin{array}{l}\text { oapparent sensory disturbance } \\
\text { ominimal sensory disturbance } \\
\text { onormal }\end{array}$ & $\begin{array}{l}0 \\
1 \\
2\end{array}$ \\
\hline Bladder function & $\begin{array}{l}\text { ourinary retention } \& / \text { or incontinence } \\
\text { osense of retention \&/ or thin stream \&/or incomplete continence urinary retardation \&/or pollakiuria } \\
\text { onormal }\end{array}$ & $\begin{array}{l}0 \\
1 \\
2\end{array}$ \\
\hline
\end{tabular}

Table 2: Japanease orthopedic association (JOA) scoring system for cervical function.

\begin{tabular}{|l|l|l|l|}
\hline & ACDF group & CTDR group & Palue \\
\hline Follow-up duration & 26.7 months & 22.84 months \\
\hline Number & 33 & 28 & \\
\hline Sex (Male/Female) & $19 / 14$ & $17 / 11$ & 0.726 \\
\hline Age & $46.8 \pm 16.9$ & $43.3 \pm 14.4$ & $15.7 \pm 11.7$ \\
\hline Preop overall CSA & $14.6 \pm 9.8$ & $2.1 \pm 3.7$ & 0.597 \\
\hline Preop SA (treated level) & $2.6 \pm 4.1$ & $40.3 \pm 13.5$ \\
\hline Preop overall cervical ROM & $37.2 \pm 11.7$ & $7.4 \pm 5.1$ \\
\hline Preop treated level ROM & $7.2 \pm 4.3$ & $9.8 \pm 6.4$ \\
\hline Preop upper adjacent ROM & $9.5 \pm 7.3$ & $6.1 \pm 5.4$ \\
\hline Preop lower adjacent ROM & $6.4 \pm 6.8$ & $6.4 \pm 3.3$ \\
\hline Preop VAS of neck pain & $6.9 \pm 2.3$ & $7.2 \pm 1.4$ \\
\hline Preop VAS of radicular pain & $7.6 \pm 1.6$ & $13.2 \pm 1.9$ \\
\hline Preop JOA score & $12.5 \pm 2.4$ & 0.491 \\
\hline
\end{tabular}

*Abbreviations: ACDF: Anterior Cervical Discectomy and Fusion; CTDR: Cervical Total Disc Replacement; CSA: Cervical Sagittal Angle; SA: Segmental Angle; ROM: Range Of Motion; VAS: Visual Analogue Scale; JOA: Japanease Orthopedic Association

Table 3: Statistical results of patient's demographics according to age, sex, preoperative radiologic features, and clinical data.

group than the ACDF group, there were no significant differences in the overall cervical spine ROM between the two groups $(p>0.05)$. The ROM of the treated level was changed from $7.2 \pm 4.3$ degrees to $1.2 \pm$ 1.8 degrees in the ACDF group and from $7.4 \pm 5.1$ degrees to $6.5 \pm 4.3$ degrees in the CTDR group. At the last follow-up, it was changed to 1.0 \pm 1.2 degrees and $9.9 \pm 7.5$ degrees in each group, respectively. During the follow-up period, the ROM of the treated level was significantly higher in the CTDR group than the ACDF group $(\mathrm{p}<0.05)$. The ROM of the upper adjacent segment was $9.5 \pm 7.3$ degrees in the ACDF group and $9.8 \pm 6.4$ degrees in the CTDR group. One month after surgery, it was changed to $7.1 \pm 6.9$ degrees and $8.6 \pm 6.1$ degrees in each group, respectively. At the last follow-up, it was changed to $11.6 \pm 7.7$ degrees and $8.6 \pm 7.5$ degrees in each group, respectively (Figure 4 ). The ROM of the upper adjacent segment was significantly increased in the ACDF group compared to the CTRD group at the last follow-up $(p<0.05)$. The ROM of the lower adjacent segment was $6.4 \pm 6.8$ degrees in the ACDF group and $6.1 \pm 5.4$ degrees in the CTDR group. One month after surgery, it was changed to $6.2 \pm 5.9$ degrees and $5.6 \pm 4.3$ degrees in each group, respectively. At the last follow-up, it was changed to 6.5 \pm 5.1 degrees and $6.4 \pm 4.9$ degrees in each group, respectively. There were no statistical significances in the lower adjacent segment ROM between the two groups during the follow-up period $(\mathrm{p}>0.05)$ (Figure $5)$.

In the ACDF group, successful fusion was achieved in all patients during the follow-up period. Radiologic ASD developed in 6 cases (18.9\%) of the ACDF group and in 4 cases (14.3\%) of the CTDR group. However, there was no symptomatic ASD in both groups. Between the two groups, there was no statistical significance in the development of radiologic ASD ( $p>0.05$ ). In the CTDR group, loss of motion at the operated level was found in 3 cases, and radiologic ASD developed in the 2 out of those 3 cases.

\section{Clinical outcomes}

The preoperative VAS score for axial neck pain was $6.9 \pm 2.3$ points and for radicular pain was $7.6 \pm 1.6$ points in the ACDF group, and one month after surgery, the scores were changed to $4.5 \pm 3.1$ points and $3.0 \pm 1.4$ points, respectively. At the final follow-up, the VAS score for axial neck pain was significantly improved to $1.9 \pm 2.1$ points and the VAS score for radicular pain was also significantly improved 
Citation: Kim SD, Lee JK, Jang JW, Moon HS, Kim SH, et al. (2012) Comparison of Motion Changes and Clinical Outcomes between Cervical Disc Replacement and Anterior Cervical Discectomy and Fusion in Single Level Cervical Degenerative Disease: Retrospective Analysis. J Spine 1:116. doi:10.4172/2165-7939.1000116

Page 5 of 7
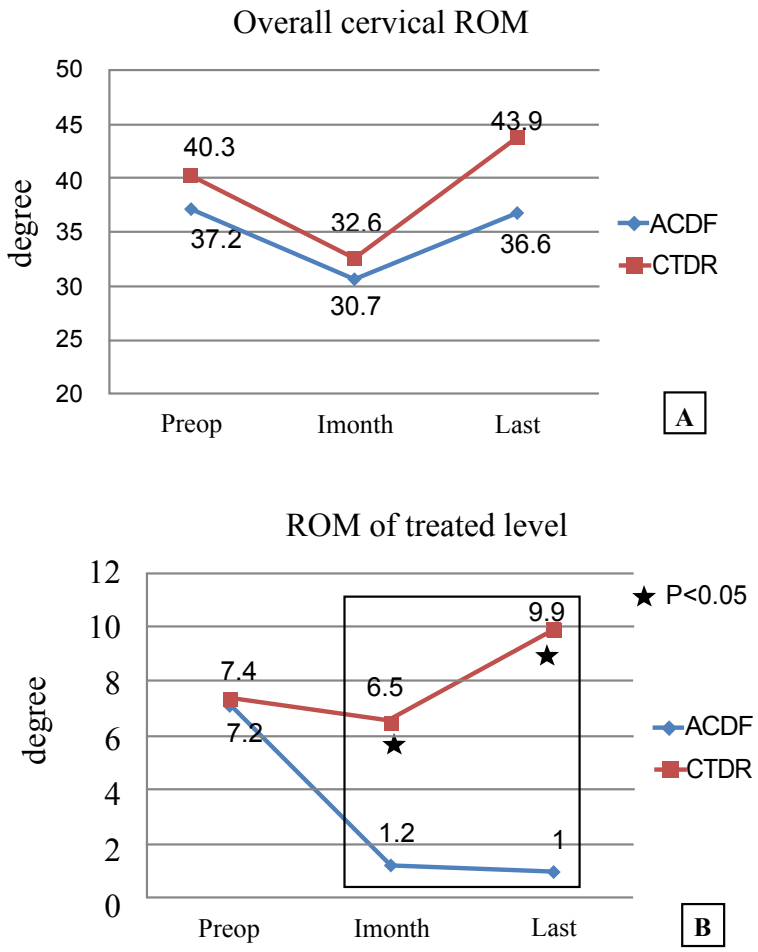

*Abbreviations: ROM: Range Of Motion

Figure 4: The changes of ROM of overall cervical spine (A) and ROM of treated level $(B)$.

to $1.6 \pm 1.2$ points $(\mathrm{p}<0.05)$. In the CTDR group, the preoperative VAS score for axial neck pain was $6.4 \pm 3.3$ points and for radicular pain was $7.2 \pm 1.4$ points, and one month after surgery, the scores were decreased to $3.2 \pm 2.9$ points and $3.1 \pm 2.1$ points, respectively. At the final follow-up, the VAS score for axial neck pain was significantly improved to $1.5 \pm 2.7$ points and the VAS score for radicular pain was also significantly improved to $1.9 \pm 1.1$ points $(\mathrm{p}<0.05)$. Statistically, there were no significant differences in the VAS scores for axial neck pain and radicular pain between the two groups during the follow-up period $(\mathrm{p}>0.05)$.

The preoperative JOA score was $12.5 \pm 2.4$ in the ACDF group and $13.2 \pm 1.9$ in the CTDR group, and it was increased to $14.3 \pm 1.8$ and $15.0 \pm 2.1$ in each group, respectively. At the last follow-up, the score was $14.8 \pm 2.0$ in the ACDF group and $15.2 \pm 1.7$ in the CTDR group. During the follow-up period, there were no statistical significances in JOA scores between the two groups $(p>0.05)$.

\section{Surgery-related complications}

In the ACDF group, the extrusion of the synthetic PEEF cage developed immediately after surgery in 1 case, and symptomatic postoperative cervical epidural hematoma developed in 1 case. Cage extrusion was treated with cage repositioning via reoperation, and symptomatic epidural hematoma was conservatively treated due to rapid resolution of neurologic symptoms. In the CTDR group, there were no surgery-related complications.

\section{Discussion}

Until now, cervical degenerative diseases that cause radiculopathy or myelopathy have been successfully managed via ACDF for the last five decades since ACDF was first introduced by Smith and Robinson $[1,8]$. Despite the satisfactory outcomes of ACDF, cervical fusion can lead to limitation of cervical motion, increase overloading to the adjacent levels, and eventually progress degeneration at adjacent levels with or without symptoms. That is, ACDF is beneficial for the symptomatic cervical lesion, but the ROM limitation of the treated level after fusion is related to additional mechanical stress at the adjacent segments, and it may initiate or aggravate degenerative changes of the other cervical levels, especially adjacent levels [7,9]. Eck et al. [9] stated that intradiscal pressure was increased by $73 \%$ at the upper adjacent segment and by $45 \%$ at the lower adjacent segment after one-level ACDF. Similarly, Gore et al. [10] described 14\% of patients in their study who required additional surgical intervention for adjacent segment disease at an average follow-up of five years. Williams et al. [11] found that $17 \%$ of patient who underwent ACDF developed symptomatic ASD and required additional surgery, with an average follow-up of 4.5 years. In addition, there were also various severe complications related to ACDF, such as graft collapse, extrusion, nonunion, instrumentation failure, and donor site morbidity.

The development of CTDR as an alternative method to ACDF in cervical degenerative disease has been initiated. It could be expected that CTDR can maintain the physiologic motion after cervical decompression and disc implantation, and it may reduce or delay the onset of degenerative changes at adjacent levels. The first viable cervical prosthesis, which was introduced by Fernstorm [5] and composed of a metallic ball, did not become available until the 1990s because of a high incidence of segmental hypermobility, endplate subsidence, and clinical failure. Recently, several cervical artificial discs have been introduced and these have been used in patients with cervical degenerative disease.



ROM of lower adjacent segment

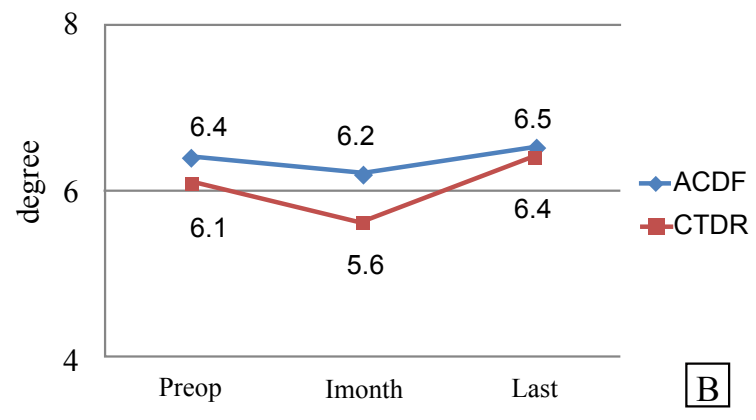

Figure 5: The changes of ROM of upper adjacent segment $(A)$ and lower adjacent segment $(B)$. 
Citation: Kim SD, Lee JK, Jang JW, Moon HS, Kim SH, et al. (2012) Comparison of Motion Changes and Clinical Outcomes between Cervical Disc Replacement and Anterior Cervical Discectomy and Fusion in Single Level Cervical Degenerative Disease: Retrospective Analysis. J Spine 1:116. doi:10.4172/2165-7939.1000116

Page 6 of 7

\section{Changes of segmental angle and cervical sagittal alignment}

To investigate the efficacy of CTDR in cervical degenerative disease, a study comparing the results of CTDR to those of ACDF in terms of cervical alignment, motion changes, and development of ASD is required. The maintenance or restoration of physiologic overall CSA and SA of the treated level is essential for a favorable clinical outcome after cervical spine surgery. Katsuura et al. [12] reported that patients with reduction of cervical lordosis or kyphotic changes after ACDF were related to the development of symptomatic ASD. In particular, they found that symptomatic ASD occurred in $77 \%$ of cases with operative level kyphosis. Furthermore, Kawakami et al. [13] demonstrated a positive correlation between fused level kyphosis and the development of axial neck pain after ACDF. In this study, the overall CSA and SA of the treated level were slightly increased one month after surgery. However, overall CSA was decreased to 0.7 degrees, and the SA of the treated level was decreased to 0.5 degrees at the last follow-up. The author used a synthetic PEEK cage for ACDF, and this cage had some degrees of a lordotic angle. Therefore, the overall CSA and segmental angle of the treated level might be increased due to the lordotic angle of the PEEK cage at one month after surgery. However, during the follow-up period, the lordotic change was slightly decreased. In the ACDF group, a stand-alone synthetic PEEK cage without plate fixation was performed, and subsidence of the treated level was observed in many cases of ACDF. Therefore, the loss of the cervical lordotic angle including SA at the last follow-up might have occurred due to cage subsidence. On the other hand, CTDR facilitated 1.2 degrees increase in the overall CSA and 2.4 degrees increase in the SA of the treated level at the last follow-up. Although there was no significant difference in the overall CSA between the two groups at the last follow-up, the SA of the treated level was significantly higher in CTDR than that in ACDF. Despite the relative short-term follow-up study, the result suggests that CTDR using a Bryan cervical artificial disc may be superior in maintaining of the SA of the treated level than the stand-alone ACDF.

There are several studies about the development of kyphosis at the treated level following CTDR using a Bryan cervical artificial disc [14-17]. Pickett et al. [15] first reported a loss of segmental lordosis of the treated level in their 14 patients treated with CTDR who had a decreased angle of lordosis, with a mean change of 6 degrees at follow-up. Others reported a loss of 2 degrees in the treated level with a decrease in the overall CSA of 4 degrees [16,17]. Although the loss of the SA of the treated level is generally compensated for by multiple other cervical levels, the loss of segmental lordosis seems to be a counterproductive result to the goal of CTDR for the restoration of physiologic biomechanics and maintenance of physiologic cervical lordosis. Several factors related to the development of local kyphosis after CTDR using a Bryan cervical artificial disc have been reported in the literature $[16,18]$. They are insertion angle of prosthesis, insertion depth and the degree of milling of the endplate, removal of the posterior longitudinal ligament, preexisting segmental kyphosis, and individual surgeon's differences. In this study, the author used fluoroscopy (C-arm) to make the decision regarding the prosthesis height, depth, and width, and the implantation of the artificial disc. The SA had been well maintained with lordosis until the last follow-up. An accurate decision regarding the artificial disc size and adequate positioning might be important to reduce the development of kyphotic change after CTDR using a Bryan cervical artificial disc.

\section{Motion changes}

A study about the motion changes after CTDR is very important to clarify the efficacy of the CTDR compared to ACDF. In this study, the
ROM of the treated level in the CTDR group at the last follow-up was well maintained, with a slight increase compared to the preoperative ROM. However, the ROM of the treated level in the ACDF group was significantly decreased. These results were similar to previously published data $[15,19]$. That is, the ROM of the treated level was well maintained in the CTDR group compared to the ACDF group. The ROM of the cervical spine was decreased from 37.2 degrees to 30.7 degrees in the ACDF group and from 40.3 degrees to 32.6 degrees in the CTDR group one month after surgery. However, it was increased to 36.9 degrees and 43.9 degrees at the last follow-up in both groups, respectively. In the treated level, a slight decrease of ROM was also observed in both groups at one month after surgery. One month after surgery, the VAS for axial neck pain was 4.5 points in the ACDF group and 3.2 points in the CTDR group. The ROM of the cervical spine and treated level might be temporarily decreased due to remaining axial neck pain during the early postoperative period. The ROM of the cervical spine was similar in the ACDF group and increased in the CTDR group compared to the preoperative ROM of the cervical spine at the last follow-up. Although statistical significance of the ROM of cervical spine was not observed between the two groups at the last follow-up, the CTDR group had a tendency to an increase of the ROM of the cervical spine.

Park et al. [20] demonstrated that the upper adjacent segmental motion was significantly increased in the ACDF group compared to a slight reduction in the CTDR group. In this study, the ROM of the upper adjacent segment was decreased in both groups at one month after surgery. However, the ROM of the upper adjacent segment was increased in the ACDF group at the last follow-up, and it was significantly higher in the ACDF group than that in the CTDR group. One month after surgery, postoperative axial neck pain remained and it might have led to a decrease in the cervical spine ROM including the treated level ROM and upper adjacent segmental ROM in both groups. During the follow-up period, an increase of upper adjacent segmental ROM was observed only in the ACDF group. These findings suggest that hyper-mobility of the upper adjacent segment after cervical spine surgery could be prevented by artificial disc replacement. On the other hand, there were no significant differences in the lower adjacent segment ROM between the two groups at preoperatively, one month after surgery, and the last follow-up. Regarding motion changes, further study will be required to investigate whether the upper adjacent segment is affected more than the lower adjacent segment after anterior cervical spine surgery in either ACDF or CTDR.

\section{Adjacent segment degeneration}

The question, "Is it true that CTDR can reduce the development of ASD compared to ACDF", is a hot topic. Robertson et al. [7] reported that CTDR reduced the incidence rate of ASD compared to ACDF in their two-year follow-up study. Yi et al. [18] reported that the rate of radiologic ASD after CTDR was higher than that observed in previously reported studies, when $\mathrm{HO}$ was included as a tendency of ASD. In this study, symptomatic ASD did not develop during the follow-up period. Radiologic ASD was observed in 18\% (6/33 cases) of the ACDF group and $14 \%$ (4/28cases) of the CTDR group and there was no statistical significance. Unfortunately, loss of motion in the CTDR group was observed in 3 cases during follow-up, and radiologic ASD developed in 2 out of those 3 cases. Therefore, radiologic ASD was developed in approximately $8 \%(2 / 25$ cases) of the cases with motion preservation of the treated level after CTDR. This finding suggests that maintenance of treated level ROM may be important to reduce the development or progression of radiologic ASD. However, in this study, the role of 
Citation: Kim SD, Lee JK, Jang JW, Moon HS, Kim SH, et al. (2012) Comparison of Motion Changes and Clinical Outcomes between Cervical Disc Replacement and Anterior Cervical Discectomy and Fusion in Single Level Cervical Degenerative Disease: Retrospective Analysis. J Spine 1:116. doi:10.4172/2165-7939.1000116

Page 7 of 7

CTDR for prevention of symptomatic ASD remained unclear due to the relatively short-term follow-up period.

\section{Comparison of clinical outcome after CTDR and ACDF}

Sasso et al. [19] studied 115 cases randomized in a 1:1 ratio to ACDF or CTDR for two years. They reported that CTDR had favorable outcomes compared to the ACDF group. Another study showed that CTDR maintained physiologic segmental motion at two years after implantation and was associated with improved neurological success, improved clinical outcomes, and a reduced rate of secondary surgeries compared to ACDF [21]. In this study, several differences in radiologic results between ACDF and CTDR were demonstrated during the follow-up period of about two years. However, there were no statistical significances in clinical outcomes with VAS and JOA scores between the two groups. Initial clinical outcomes after anterior cervical surgery for cervical degenerative disc disease were associated with a correct diagnosis, adequate decompression, and stabilization of the pathologic lesion. Therefore, both CTDR and ACDF could provide early favorable clinical outcomes after surgery. Clinically, the most important goals of CTDR are to reproduce normal cervical kinematics and alignment, prevent radiological and symptomatic ASD, and eventually reduce secondary operation at the adjacent segment. Therefore, a long term follow-up study about the relationship between the radiologic changes including ASD and clinical outcomes via comparison to ACDF will be essential to assess the clinical advantages of CTDR.

\section{Conclusion}

Good clinical and radiologic outcomes suggest that CTDR might be a safe and effective alternative to traditional ACDF in degenerative cervical disease. About two years after surgery, CTDR using a Bryan cervical artificial disc can maintain the ROM of the treated level and prevent hyper-mobility of the upper adjacent segment compared to ACDF. Although there was no statistical significance in radiologic ASD development between the ACDF and CTDR groups, the maintenance of the motion at the treated level after CTDR may be important to prevent the development of radiologic ASD. Clinically, there were no significant differences in VAS and JOA scores between the two groups during the follow-up period. Therefore, a long-term follow-up study with a large number of patients will be mandatory to evaluate the clinical efficacy of CTDR.

\section{References}

1. Smith GW, Robinson RA (1958) The treatment of certain cervical-spine disorders by anterior removal of the intervertebral disc and interbody fusion. $J$ Bone Joint Surg Am 40-40A: 607-624

2. Bohlman HH, Emery SE, Goodfellow DB, Jones PK (1993) Robinson anterior cervical discectomy and arthrodesis for cervical radiculopathy. Long-term follow-up of one hundred and twenty-two patients. J Bone Joint Surg Am 75: 1298-1307.

3. Hilibrand AS, Carlson GD, Palumbo MA, Jones PK, Bohlman HH (1999) Radiculopathy and myelopathy at segments adjacent to the site of a previous anterior cervical arthrodesis. J Bone Joint Surg Am 81: 519-528.

4. Song KJ, Taghavi CE, Hsu MS, Lee KB, Kim GH, et al. (2010) Plate augmentation in anterior cervical discectomy and fusion with cage for degenerative cervical spinal disorders. Eur Spine J 19: 1677-1683.

5. Fernstrom $U$ (1966) Arthroplasty with intercorporal endoprothesis in herniated disc and in painful disc. Acta Chir Scand Suppl 357: 154-159.

6. Büttner-Janz K, Schellnack K, Zippel H (1989) Biomechanics of the SB Charité lumbar intervertebral disc endoprosthesis. Int Orthop 13: 173-176.

7. Robertson JT, Papadopoulos SM, Traynelis VC (2005) Assessment of adjacentsegment disease in patients treated with cervical fusion or arthroplasty: a prospective 2-year study. J Neurosurg Spine 3: 417-423.
8. Goffin J, Geusens E, Vantomme N, Quintens E, Waerzeggers Y, et al. (2004) Long-term follow-up after interbody fusion of the cervical spine. J Spinal Disord Tech 17: 79-85.

9. Eck JC, Humphreys SC, Lim TH, Jeong ST, Kim JG, et al. (2002) Biomechanical study on the effect of cervical spine fusion on adjacent-level intradiscal pressure and segmental motion. Spine (Phila Pa 1976) 27: 2431-2434.

10. Gore DR, Sepic SB (1984) Anterior cervical fusion for degenerated or protruded discs. A review of one hundred forty-six patients. Spine (Phila Pa 1976) 9: 667671.

11. Williams JL, Allen MB Jr, Harkess JW (1968) Late results of cervical discectomy and interbody fusion: some factors influencing the results. J Bone Joint Surg Am 50: 277-286

12. Katsuura A, Hukuda S, Saruhashi Y, Mori K (2001) Kyphotic malalignment after anterior cervical fusion is one of the factors promoting the degenerative process in adjacent intervertebral levels. Eur Spine J 10: 320-324.

13. Kawakami M, Tamaki T, Yoshida M, Hayashi N, Ando M, et al. (1999) Axial symptoms and cervical alignments after cervical anterior spinal fusion for patients with cervical myelopathy. J Spinal Disord 12: 50-56.

14. Johnson JP, Lauryssen C, Cambron HO, Pashman R, Regan JJ, et al. (2004) Sagittal alignment and the Bryan cervical artificial disc. Neurosurg Focus 17: E14.

15. Pickett GE, Mitsis DK, Sekhon LH, Sears WR, Duggal N (2004) Effects of a cervical disc prosthesis on segmental and cervical spine alignment. Neurosurg Focus 17: E5.

16. Sears WR, Duggal N, Sekhon LH, Williamson OD (2007) Segmental malalignment with the Bryan cervical disc prosthesis--contributing factors. J Spinal Disord Tech 20: 111-117.

17. Sears WR, Sekhon LH, Duggal N, Williamson OD (2007) Segmental malalignment with the Bryan Cervical Disc prosthesis--does it occur? J Spinal Disord Tech 20: 1-6.

18. Yi S, Shin HC, Kim KN, Park HK, Jang IT, et al. (2007) Modified techniques to prevent sagittal imbalance after cervical arthroplasty. Spine (Phila Pa 1976) 32: 1986-1991.

19. Sasso RC, Best NM, Metcalf NH, Anderson PA (2008) Motion analysis of bryan cervical disc arthroplasty versus anterior discectomy and fusion: results from a prospective, randomized, multicenter, clinical trial. J Spinal Disord Tech 21 393-399.

20. Park JH, Roh KH, Cho JY, Ra YS, Rhim SC, et al. (2008) Comparative analysis of cervical arthroplasty using mobi-c(r) and anterior cervical discectomy and fusion using the solis(r) -cage. J Korean Neurosurg Soc 44: 217-221.

21. Mummaneni PV, Robinson JC, Haid RW Jr (2007) Cervical arthroplasty with the PRESTIGE LP cervical disc. Neurosurgery 60: 310-314. 